\title{
Corrosion Prevention of Aluminium in 1 M HCl by Surface Deposition of Nickel Titanate
}

\author{
K.S. Beenakumari * \\ Department of Chemistry, All Saints' College,Thiruvananthapuram, Kerala, 695007 - India
}

Received 17 January 2013; accepted 27 August 2013

\begin{abstract}
A different approach for protecting the aluminium in $1 \mathrm{M} \mathrm{HCl}$ is done by strengthening the surface oxide film of aluminium with nickel titanate particles. Weight loss methods, open circuit potential measurements and polarization techniques are used to measure the corrosion behaviour of aluminium samples. The corrosion rate of nickel titanate deposited aluminium shows lower values compared to pure aluminium in $\mathrm{HCl}$ medium. The intermixing of aluminium oxide with nickel titanate enhances the corrosion resistance property of the aluminium oxide layer on the surface of aluminium and thereby reduces the coulombic and non-coulombic loss of metal.
\end{abstract}

Keywords: aluminium, corrosion, nickel titanate, $\mathrm{HCl}$, polarization.

\section{Introduction}

Aluminum and its alloys are widely used in industries and domestic applications due to lightweight, high thermal and electrical conductivity [1-4]. Aluminium is always associated with a passive oxide film on its surface [5-7]. The kinetics of aluminium dissolution is reduced by the presence of the oxide film [8]. The protective film is broken either by the attack of chloride ions in the solution or by the action of strong alkaline solutions [8-11]. There are many techniques to prevent the corrosion of aluminium in hydrochloric acid solution and the common method is the use of corrosion inhibitors [3, 5, 10-12]. The majority of corrosion inhibitors are synthetic chemicals. They are toxic in nature, very expensive, and non-degradable. A different approach is applied to protect the aluminium in chloride environment by strengthening the surface oxide film by depositing nickel titanate particles. In literature, nickel titanate coatings are used to reduce friction and wear in high temperature applications [13-17]. The nickel

\footnotetext{
* Corresponding author. E-mail address: beenagireesh@yahoo.co.uk
} 
titanate coatings provide resistant against oxidizing atmospheres [17, 18]. The nickel titanate particles were prepared by co-precipitation method from a solution containing both nickel and titanium ions. The co-precipitation techniques have many advantages over other techniques like combustion method, such as homogeneity in the phase of reactant, stoichiometric control, high purity and ease of processing [19, 20]. The nickel titanate particle precipitated by coprecipitation method is simultaneously deposited on aluminium surfaces by dipping the pre-treated aluminium specimen in the nickel titanate preparation bath.

\section{Experimental}

The substrate selected was aluminium plate of purity $98.1 \%$. Rectangular strips of size $5 \mathrm{~cm} \times 2 \mathrm{~cm} \times 1 \mathrm{~cm}$ were cut from aluminium plate. These strips were abraded with fine emery papers, degreased with ethanol, washed with water and dried. For preparing $\mathrm{NiTiO}_{3}$, nickel chloride and titanium tetrachloride were used as the starting material. $\mathrm{TiCl}_{4}(0.2 \mathrm{~mol})$ and $\mathrm{NiCl}_{2}(0.2 \mathrm{~mol})$ are respectively dissolved in $1000 \mathrm{~mL}$ of distilled water. An aqueous solution containing ions of titanium and nickel in an equimolar ratio is prepared by admixing $100 \mathrm{~mL} \mathrm{TiCl}_{4}$ solution and $100 \mathrm{~mL}$ of $\mathrm{NiCl}_{2}$ solution (solution 1). A mixed solution is prepared by admixing $20 \mathrm{~mL}$ of $30 \% \mathrm{H}_{2} \mathrm{O}_{2}$ solution, $15 \mathrm{~mL}$ of $28 \%$ aqueous ammonia solution, and rest of distilled water (solution 2). The aluminium specimen prepared after pre-treatment procedure was immersed in solution 1 . The mixed solution (solution 2) is added at a rate of $10 \mathrm{~mL}$ per minute to the aqueous solution containing ions of titanium and nickel in an equimolar ratio (solution 1 with mild steel specimen) with stirring to precipitate of nickel titanate on metal surface. The specimen is then dried and kept in desiccators.

Cathodic and anodic polarization studies were carried out by using self made tri electrode assembly. Aluminium electrode (surface area $1 \mathrm{~cm}^{2}$ ) immersed in $1 \mathrm{M}$ $\mathrm{HCl}$ acts as working electrode, stainless steel (SS $316 \mathrm{~L}$ ) (surface area $20 \mathrm{~cm}^{2}$ ) acts as counter electrode. A Saturated Calomel Electrodes (SCE) served as the reference electrode for measuring the potential of the working electrode. A rheostat was used to adjust the resistance in the circuit and multimeters are used to measure current and voltage. The open circuit potential was measured as V vs. SCE.

X-ray diffraction studies were carried out for the corrosion product of the metal samples by using $\mathrm{CuK} \alpha$ radiation (Rigaku XRD instrument). Average crystalline size was calculated using Scherer equation. The corrosion rate is measured by using the conventional weight loss method by taking the difference in weight of the specimen before and after immersion in $1 \mathrm{M} \mathrm{HCl}$ solution. Corrosion rate was calculated using the equation

\section{Corrosion rate $(\mathrm{mpy})=534 \mathrm{~W} / \mathrm{dAT}$}

$\mathrm{W}$ is the weight loss of metal in milligram, $\mathrm{d}$ is the density expressed in grams per cube centimeters $\left(\mathrm{g} / \mathrm{cm}^{3}\right), A$ is the specimen area in inch $^{2}$ and $\mathrm{T}$ is the exposure time in hours. 


\section{Results and discussion}

\section{Electrochemical measurements}

OCP decay

The open circuit potential (OCP) variation of the aluminium electrodes is shown in Fig. 1.

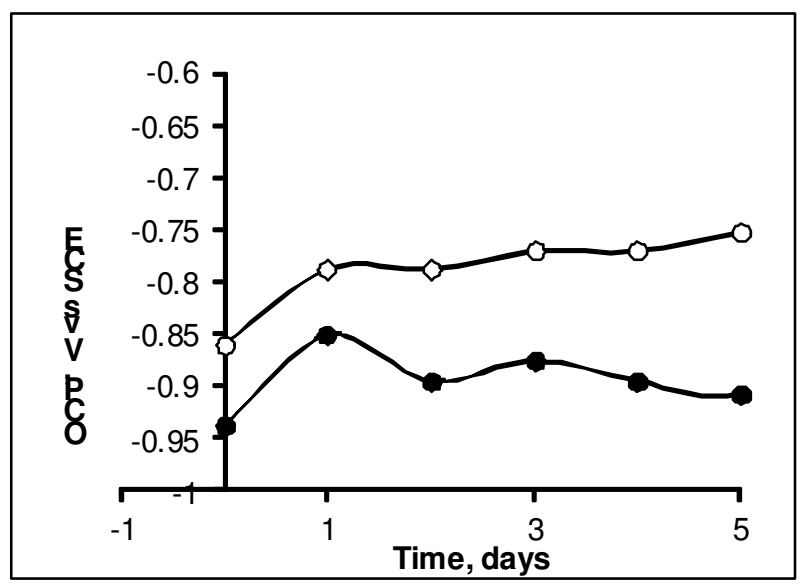

Figure 1. OCP decay of aluminium samples in $1 \mathrm{M} \mathrm{HCl}$. - pure aluminium $\circ-$ aluminium deposited with nickel titanate.

The OCP values for nickel titanate deposited aluminium samples are found to be more anodic compared to pure aluminium specimen. The OCP values for nickel titanate coated aluminium retain its anodic behavior even after 5 days of immersion in $1 \mathrm{M} \mathrm{HCl}$. The nickel titanate deposited on the aluminium enhances the resistance of the oxide layer on the aluminium and thereby shifting the potential to passive regions (anodic). The steady anodic OCP values for nickel titanate coated electrode reveals the adherence of nickel titanate on the surface of aluminium even after the prolonged exposure of metal in acid medium.

\section{Polarization resistance}

The polarization data of the electrode immersed in $1 \mathrm{M} \mathrm{HCl}$ solution is given in Table 1. The extent of polarization of aluminium with nickel titanate was lower than that of pure aluminium. Impregnation of nickel titanate shifts the slope of both anodic and cathodic polarization and thereby decreasing the corrosion current density $\left(i_{\text {corr }}\right)$ and increasing the polarization resistance of the metal. Polarization resistance is directly proportional to the surface resistivity of the metal when the metal is in contact with the electrolyte medium. Hence the resistance of the aluminium oxide layer is improved by the incorporation of nickel titanate.

Table 1. Polarization data of aluminium specimen in $1 \mathrm{M} \mathrm{HCl}$.

\begin{tabular}{|l|c|c|c|c|}
\hline Samples & $\begin{array}{c}\boldsymbol{\beta a} \\
\text { (V/decade) }\end{array}$ & $\begin{array}{c}\boldsymbol{\beta C} \\
\text { (V/decade) }\end{array}$ & $\begin{array}{c}\mathbf{E}_{\text {corr }} \\
(\mathbf{V} \text { vs. SCE) }\end{array}$ & $\begin{array}{c}\mathbf{I}_{\text {corr }} \\
\left(\mathbf{m A} \mathbf{\text { cm }} \mathbf{c m}^{\mathbf{2}}\right)\end{array}$ \\
\hline Aluminium & 0.190 & -0.260 & -0.840 & 3.820 \\
\hline $\begin{array}{l}\text { Aluminium with } \\
\text { nickel titanate }\end{array}$ & 0.120 & -0.250 & -0.800 & 0.998 \\
\hline
\end{tabular}




\section{Corrosion rate measurements}

The corrosion rate of aluminium with and without incorporation of nickel titanate in $1 \mathrm{M} \mathrm{HCl}$ is given in Table 2. The corrosion rate of nickel titanate incorporated aluminium in $1 \mathrm{M} \mathrm{HCl}$ shows lower value compared to pure aluminium metal. This is due to the strengthening of the oxide film on the surface of aluminum by nickel titanate and thereby reduces the ionic and non-ionic dissolution of aluminium.

Table 2. Corrosion rate of specimens in $1 \mathrm{M} \mathrm{HCl}$ medium.

\begin{tabular}{|l|c|c|}
\hline \multicolumn{1}{|c|}{ Specimen } & OCP (V vs. SCE) & Corrosion rate (mpy) \\
\hline aluminium & -0.845 & 11.6 \\
\hline $\begin{array}{l}\text { aluminium with nickel } \\
\text { titanate on its surface }\end{array}$ & -0.800 & 6.12 \\
\hline
\end{tabular}

Table 3. XRD data of corrosion product of aluminium metal samples.

\begin{tabular}{|c|c|c|c|c|}
\hline Specimens & $\begin{array}{c}\text { Peak } \\
\text { at 20 }\end{array}$ & $\begin{array}{c}\text { Peak } \\
\text { corresponding }\end{array}$ & $\begin{array}{c}\boldsymbol{\beta} \text { 1/2 } \\
\text { (radians) }\end{array}$ & $\begin{array}{c}\text { Particle size } \\
\text { (nm) }\end{array}$ \\
\hline \multirow{2}{*}{$\begin{array}{c}\text { Aluminium without } \\
\text { nickel titanate }\end{array}$} & 34.1 & $\mathrm{Al}_{2} \mathrm{O}_{3}$ & 0.001163 & 117 \\
\cline { 2 - 5 } & 38.9 & $\mathrm{Al}$ & 0.001260 & 108 \\
\hline \multirow{2}{*}{$\begin{array}{c}\text { Aluminium with } \\
\text { nickel titanate }\end{array}$} & 37.8 & $\mathrm{NiTiO}_{3}$ & 0.003020 & 45.3 \\
\cline { 2 - 5 } & 34.2 & $\mathrm{Al}_{2} \mathrm{O}_{3}$ & 0.001256 & 109 \\
\cline { 2 - 5 } & 39.0 & $\mathrm{Al}$ & 0.001368 & 100 \\
\hline
\end{tabular}

\section{XRD analysis}

The extent of surface interaction of nickel titanate with aluminium oxide can be revealed only by XRD analysis. Table 3 shows the XRD data of corrosion product scratched from the aluminium surface (with and without incorporation of nickel titanate) after exposure in $1 \mathrm{M} \mathrm{HCl}$ for 1 day. The XRD analysis reveals the presence of nickel titanate, aluminium oxide and aluminium on the aluminium electrode coated with nickel titanate. This shows the strong interaction and intermixing of aluminium oxide and nickel titanate on the surface of aluminium. This modified aluminium oxide layer enhances the corrosion prevention of aluminium in chloride environment.

\section{Conclusion}

A new method of corrosion prevention of aluminium in $1 \mathrm{M} \mathrm{HCl}$ was developed by depositing nickel titanate particles on the surface of aluminium. The nickel titanate particles were prepared by co- precipitation method from an aqueous solution containing ions of titanium and nickel, to an aqueous alkaline solution containing hydrogen peroxide and these nickel titanate particles produced were in-situ deposited on aluminium surfaces. The intermixing of nickel titanate with aluminium oxide on the surface of aluminium enhances the corrosion resistance property of the oxide layer on the surface of aluminium and thereby preventing the coulombic and non-coulombic loss of metal. 


\section{References}

1. Li X, Nie X, Wang L, Nothwood DO. Surf Sci Coat Tech. 2005;200:1994.

2. Sherif EM, Park S. Electrochim Acta. 2006;51:1313.

3. Ali AN, Foaud N. J Mater Environ Sci. 2012;3:917.

4. Desai PS, Vashi RT. Ind J Chem Tech. 2010;17:50.

5. Burleigh TD, T Smith A. J Electrochem. Soc. 1992;139:2799.

6. Lee EJ, Pyun SJ. Corros Sci. 1995;37:157.

7. Rethinnagiri V, Jeyaprakash P, Arunkumar M, et al. Adv App Sci Res. 2012;3:1718.

8. Amin MA, EI-Rehim SSA, El-Sherbini EEF, et al. Corros Sci. 2009;51:658.

9. Albert IJ, Kulandainathan M, Ganesan MA, et al. J Appl Electrochem. 1989;19:547.

10. Nisancioglu K, Holtan H. Electrochim Acta. 1979;24:1229.

11. El-Etre AY. Corros Sci. 2003;45:2485.

12. James AO, Oforka NC, Abiola OK. Bull.Electrochem. 2006;22:111.

13. Singh RS, Ansari TH, Singh RA, et al. Mater Chem Phys.1995;50:173.

14. Taylor DJ, Fleg PF, Page RA. Thin Solid Films. 2002;408:104.

15. Murughan AV, Samuel V, Navale SC, et al. Mater Lett. 2006;60:1791.

16. Lerch M, Boysen H, Nerder R, et al. J Phys Chem Sol.1992;53:1153.

17. Marcilly C, Courty P, Delmon BJ. J Am Ceram Soc. 1970;53:56.

18. Page RA, Blanchard-Ardid CR, Wei W. J Mater Sci.1988;23:946.

19. Beenakumari KS. J Exp Nano Sci. 2013;8:213.

20. Beenakumari KS. Mater Sci Res Ind. 2009;6:235. 